\title{
Engineering the Propagation of High-k Bulk Plasmonic Waves in Multilayer Hyperbolic Metamaterials by Multiscale Structuring
}

Zhukovsky, Sergei; Lavrinenko, Andrei; Sipe, John E.

Publication date:

2013

Link back to DTU Orbit

Citation (APA):

Zhukovsky, S., Lavrinenko, A., \& Sipe, J. E. (2013). Engineering the Propagation of High-k Bulk Plasmonic Waves in Multilayer Hyperbolic Metamaterials by Multiscale Structuring. Abstract from 15th Photonics North Conference, Ottawa, Canada.

\section{General rights}

Copyright and moral rights for the publications made accessible in the public portal are retained by the authors and/or other copyright owners and it is a condition of accessing publications that users recognise and abide by the legal requirements associated with these rights.

- Users may download and print one copy of any publication from the public portal for the purpose of private study or research.

- You may not further distribute the material or use it for any profit-making activity or commercial gain

- You may freely distribute the URL identifying the publication in the public portal

If you believe that this document breaches copyright please contact us providing details, and we will remove access to the work immediately and investigate your claim. 


\title{
Engineering the Propagation of High-k Bulk Plasmonic Waves in Multilayer Hyperbolic Metamaterials by Multiscale Structuring
}

\author{
Sergei V. Zhukovsky ${ }^{1}$, Andrei V. Lavrinenko ${ }^{1}$, and John E. Sipe ${ }^{2}$ \\ ${ }^{1}$ DTU Fotonik - Department of Photonics Engineering, Technical University \\ of Denmark, ${ }^{2}$ Department of Physics, University of Toronto, Canada
}

Subwavelength metal-dielectric multilayers can be approximately regarded as anisotopic media having an effective permittivity tensor with components of different signs. Such multilayers, called hyperbolic metamaterials (HMMs), behave like metals or dielectrics depending on light polarization and feature exotic physical effects such as broadband singularity in the photonic density of states. It was shown that these photonic states are mainly populated by propagating high- $k$ bulk plasmons, stemming from hybridization of short-range surface plasmon polaritons (SRSPPs) supported by individual metallic layers. These high- $k$ waves can have anomalously short wavelength, which underlies the concept of far-field subwavelength imaging (hyperlensing) in HMMs. In this work, we show that propagation of these high- $k$ bulk plasmons can be controlled by modulating, or superstructuring, the filling fraction of metal in a subwavelength metal-dielectric stack on a longer, wavelength scale. The basic superstructure geometry is a hybrid multiscale HMM where the modulation itself is periodic, forming a photonic band gap (PBG) for the high- $k$ waves according to the same principles as in conventional photonic crystals. As a result, some of the propagating high- $k$ waves (those whose wave vectors satisfy the PBG condition) become evanescent again. Changing the geometry of the superstructure from periodic to more complicated can further affect the properties of high- $k$ wave propagation using known PBG-based approaches. It is thus possible to engineer a metamaterial where high- $k$ bulk plasmons with desired properties can be selectively reflected, transmitted, localized, suppressed or enhanced. As an example, we propose several designs of proofof-principle multiscale devices such as Bragg reflectors, Fabry-Pérot resonators, and band pass filters for high- $k$ waves. The proposed concept of multiscale HMMs can be used to tune the operation of HMM-based hyperlenses and subwavelength imaging devices. Spectrally selective multiscale HMMs can also be used to probe the spectral dependencies of HMM-induced effects, such as anomalous enhancement of spontaneous emission or blackbody radiation. In addition, the proposed structures can be employed to investigate other aspects of light-matter interaction in unusual environments. 